\title{
Does the Presence of Obesity and/or Metabolic Syndrome Affect the Course of Acute Pancreatitis? Prospective study
}

* Samer Al Sawalhi (MD,MRCS-Ireland)

*Assistant Professor-Surgical consultant Department of surgery Isra'a Hospital-Amman-Jordan (skyscraper555@yahoo.com)

\section{OBJECTIVES}

\section{METHODS}

The incidence $o$
pancreatic injury

Metabolic syndrome (MS) is defined as a cluster condition of cardiovascul Metabolic syndrome (MS) is defined as a cluster condition of cardiovascular
risk factors, including hyperglycemia, dyslipidemia, hypertension, and central obesity.

* We analyze if the presence of obesity and/or MS affects the course of pancreatitis In fact, a new severity scoring system (acute physiology and chronic health eval
proposed to consider obesity as an independent predictor for the outcome of AP. (a) Obesity is associated with an increased risk of AP development; therefore, larger abdominal adiposity The relationship between MS criteria and pancreatic diseases remains vague. In our study, we explored the relation between MS criteria based on the International Diabetic Federation an predict pancreatitis severity

\begin{tabular}{|c|c|c|c|c|c|}
\hline TABLE 1. Overall Patient $C h$ & aracteristic $(N-140)$ & 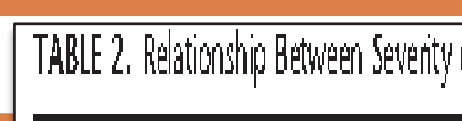 & 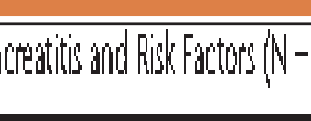 & & \\
\hline Patient Characteristics & $\begin{array}{ll}\text { Result } \\
\end{array}$ & 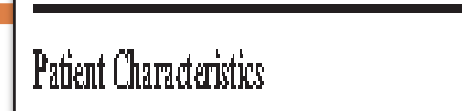 & 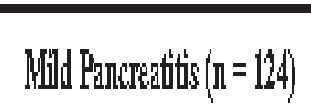 & 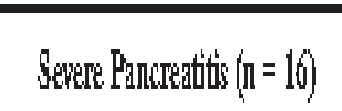 & $x^{2}+2$ \\
\hline $\begin{array}{l}\text { Age, } y \\
\text { Median, mean (SD), range }\end{array}$ & $46,48.4(17.7), 68[17.085 .0]$ & 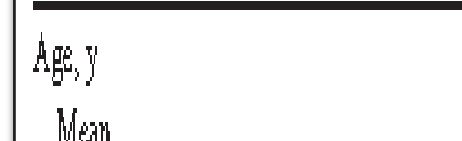 & & & 0838 \\
\hline 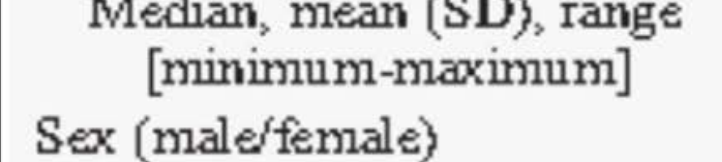 & $(60[42.9 \% / 1 / 80[57.1 \%]\})$ & 的船 & 60 & it.5 & \\
\hline 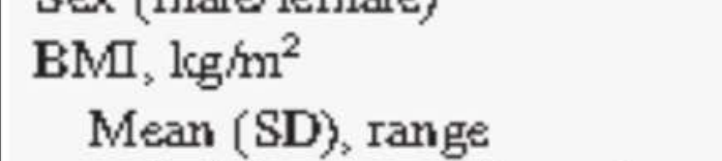 & $3016093342[140,4011$ & 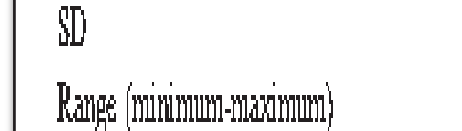 & (1) & & \\
\hline $\begin{array}{l}\text { Mean (SS), range } \\
\text { [nininumu-maximum] } \\
\text { Underefeight }\end{array}$ & $30.1[6.99), 34.2[14.949 .1]$ & 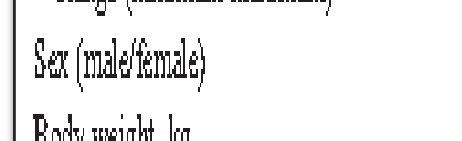 & Sit & 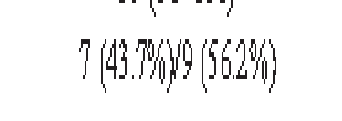 & 092 \\
\hline Nomal & $36(25.7 \%)$ & 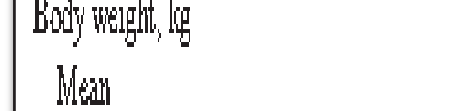 & 738 & & \\
\hline Overweight & $32(22.9 \%)$ & 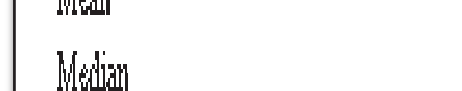 & (x) & 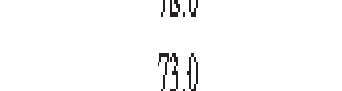 & \\
\hline Obese & $58(41.4 \%)$ & an & 63 & 2.33 & \\
\hline $\begin{array}{l}\text { Mobrid obesity } \\
\text { Central obesity }\end{array}$ & $12(8.6 \%)$ & 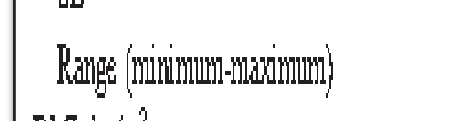 & 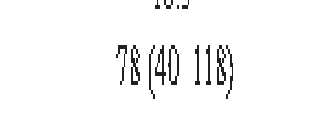 & 54866100 & \\
\hline $\mathrm{WC}, \mathrm{cm}$ & 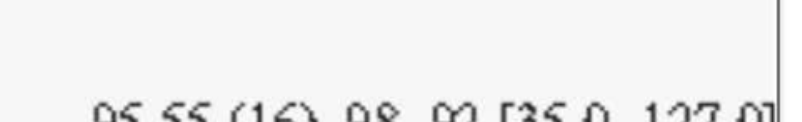 & 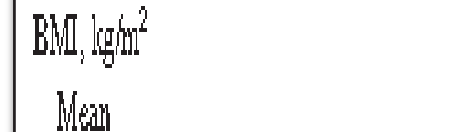 & (1) & & 0.5931 \\
\hline $\begin{array}{l}\text { Meanan (SD), range } \\
\text { [ninimumm-maximum] }\end{array}$ & $95.55(16), 9892[35.01277 .0]$ & Nation & & & \\
\hline 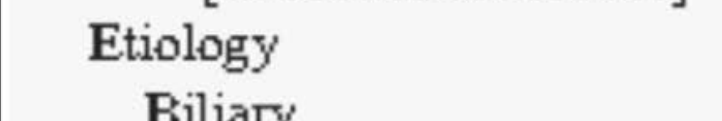 & & $\mathbb{D}$ & 71 & 59 & \\
\hline $\begin{array}{l}\text { Biliary } \\
\text { Unlcrown (idiopathic) }\end{array}$ & $34(24.3 \%)$ & 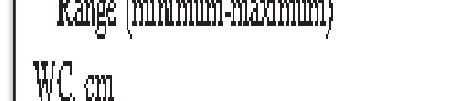 & & & 00786 \\
\hline Death (mortality) & $4(2.9 \%)$ & then & & & \\
\hline $\begin{array}{l}\text { Severinty of Pancreatitis } \\
\text { Mild }\end{array}$ & $124(88.6 \%)$ & Moin & Q9. & & \\
\hline $\begin{array}{l}\text { Severe } \\
\text { mplictions }\end{array}$ & $16(11.4 \%)$ & 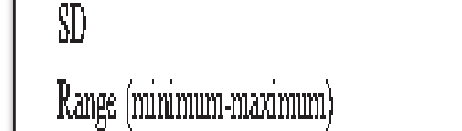 & 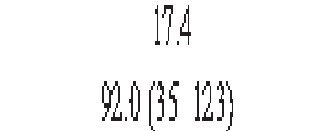 & 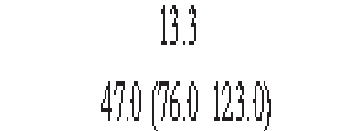 & \\
\hline $\begin{array}{l}\text { Local } \\
\text { Sortats }\end{array}$ & $\begin{array}{l}13(9.2 \%) \\
161.14063)\end{array}$ & 㱐纹 & $9(\cos 59)$ & $9(1024)$ & bisal \\
\hline
\end{tabular}

TABLE 3. Prevalence o o MS in Patiente With Panctratitis (N-140)

\begin{tabular}{|c|c|c|c|c|c|}
\hline \multicolumn{6}{|c|}{ TABLL 3. Prevalence of MS in Patientit With Panctreatitis $(N-140)$} \\
\hline Faxtor & Citteria & Total $(\mathbb{N}=140)$ & 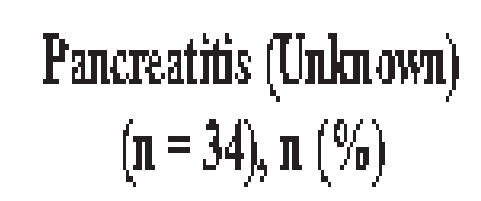 & 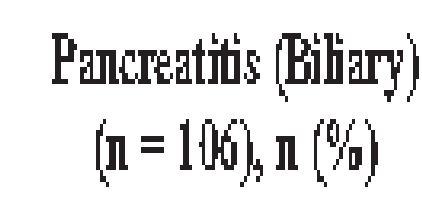 & \\
\hline \multirow{2}{*}{$\overline{M B}$} & Yes & $88(62.8 \% / 1)$ & $\theta(\theta)$ & $88(83)$ & 0.000 \\
\hline & No & $52(37.19 / 4)$ & $34(100)$ & $18(16.9)$ & \\
\hline \multirow[t]{4}{*}{ Centrad obsity, WC, , $1 \mathrm{~m}$} & $M d t, \geq 4$ & 40 & $8(23.5)$ & $32(30.1)$ & 0.03 \\
\hline & Male,,$M 4$ & 20 & $6(17.6)$ & $14(132)$ & \\
\hline & Female, 880 & 70 & $14(4.1 .1)$ & $56(22.8)$ & \\
\hline & Fendale, 480 & 10 & $6(17.6)$ & $4(3.7)$ & \\
\hline \multirow{6}{*}{$\mathrm{BMI}_{1}, \mathrm{lggm}_{\mathrm{gm}}^{2}$} & Underwe ght & 2 & $2(5.8)$ & $\theta(0)$ & 0.2 \\
\hline & Nomal weight & 36 & $12(392)$ & $24(22.6)$ & \\
\hline & Orearregeghit & 32 & $5(14.7)$ & $27(254)$ & \\
\hline & Obesed das 1 & 70 & $15(44.1)$ & $55(51.8)$ & \\
\hline & Obesece dass II & & & & \\
\hline & Obeses dasu II & & & & \\
\hline
\end{tabular}

CONCLUSIONS

The presence of MS in patients with pancreatitis is

noticeable, but it does not affect the course of disease severity, whereas obesity correlates with pancreatitis severity. Further research is warranted to expand the details of this relationship

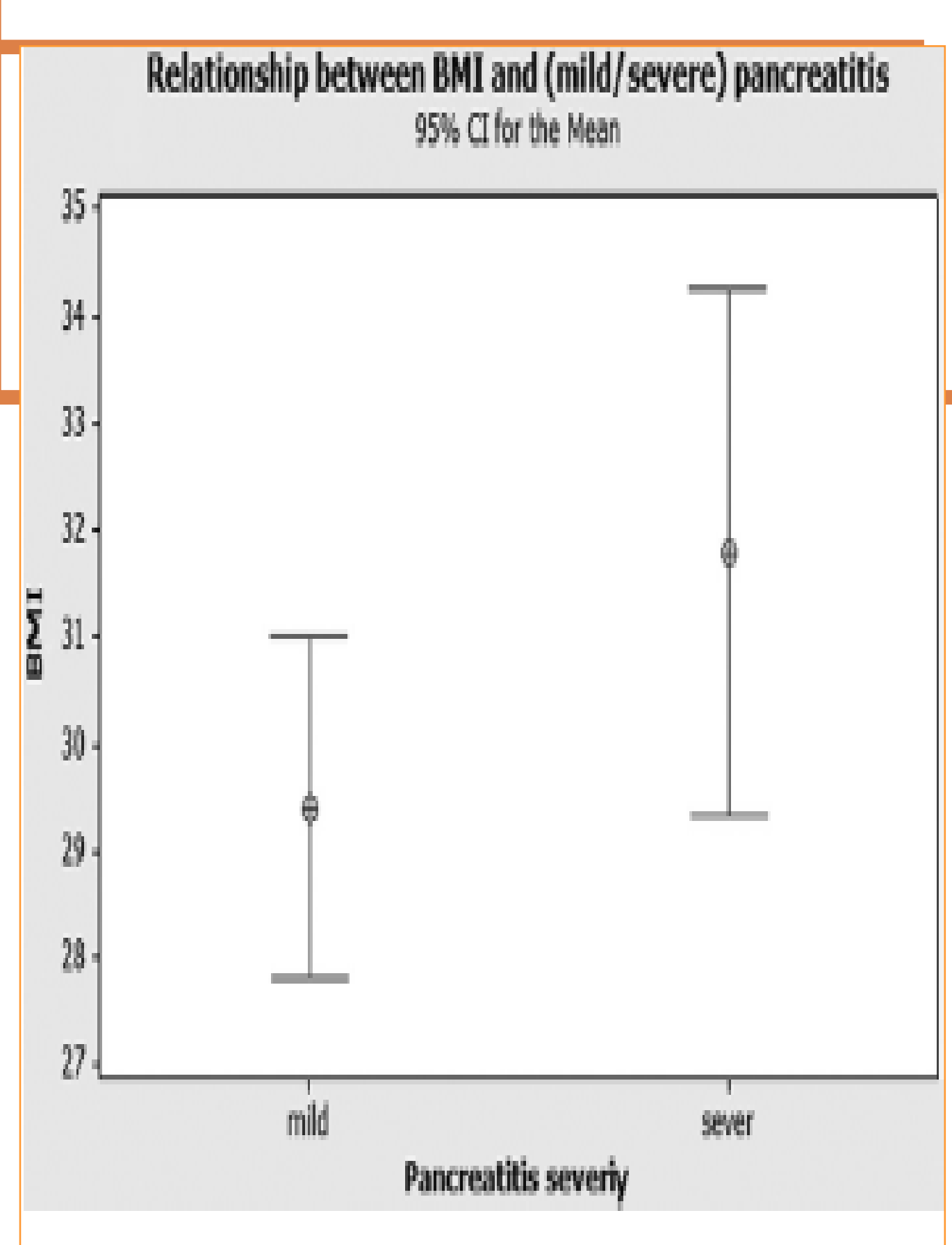

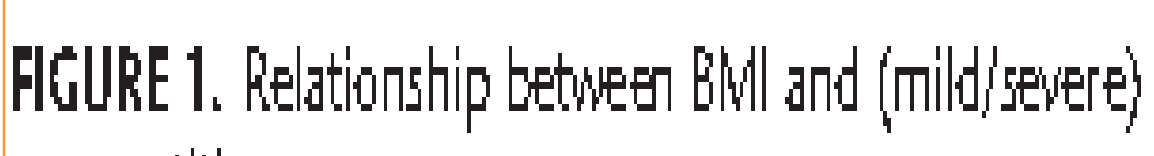
pancreatitis.

Exclusion Criteria
Patients were excluded from the study if they fell into any of the following categories: presented with recurrent pancreatitis, diabetes mellitus, hyperlipidemia or dyslipidemia, hypertension, pregnancy, presence of morbidities possibly affecting the patient's weight, such as hypothyroidism, pregnancy, alcohol consumption, history of episodes of idiopathic and chronic pancreatitis, drug
induced and pancreatic divisum, endoscopic retrograde cholangiopancreatography pancreatitis, hyperlipidemiaor hypercalcemia-induced pancreatitis, and patients with symptoms for more than 2

\section{Definition of MS}

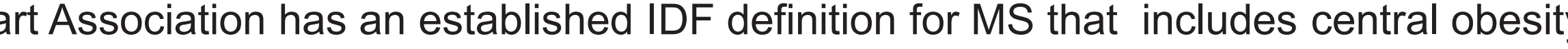
as an essential component, logether

with at least 2 of the following 4 criteria[3]

1. administering $150 \mathrm{mg} / \mathrm{dL}$ triglyceride or more or receiving drug treatment;

3.

4 , fasting blood glucose of $100 \mathrm{mg} / \mathrm{dL}$ and above.

The IDF criteria have suggested a redefinition of the MS

people in the Middle East populations.

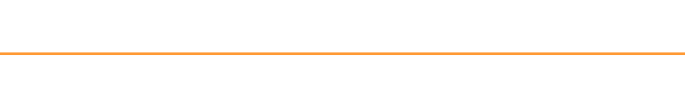

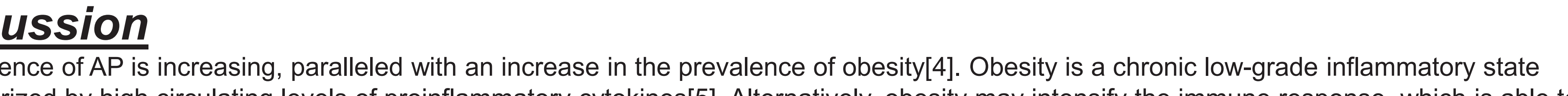

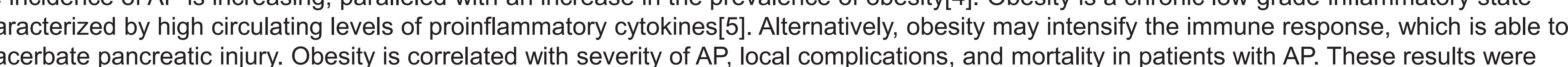
confirmed in our study and by meta-analysis[6].

obesity is also associated with higher levels of inflammatory markers[7]. Papachristou et al [1] proposed a new severity scoring system (APACHamplifying the immune response to injury

**Patients with android fat distribution and higher WC measurements are at greater risk for developing severe AP[8].

Recently, it has been shown that children with MS harbor a high risk of pancreatitis[9], suggesting that the relationship

between the risk of pancreatitis and MS is interchangeable.

-The high prevalence of MS in patients with pancreatitis with its considerable burden on the middle-aged population mandates the implementation mulation of visceral fat in patients with obesity increases the risk of severe AP although the action of adipocytokines [9] among these, serum adiponectin concentrations have been shown to be lower in patient with obesity. In addition, evaluating hypoadiponectemia may be useful for accurate

We found that body weight can predict the clinical severity of
pancreatitis with significant $P$ value $(P=0.009$; Table 2$)$.

We found that $88(62.8 \%)$ of patients with pancreatitis

(T)ed pancreatitis and BMI value (Table 3.P $=0.024$ )

we noticed that the prevalence of $\mathrm{MS}$ is more in patients with acute biliary pancreatitis $(83 \% ; \mathrm{P}=0.000$; Table 3$)$.

In our study, the risk of initial attack of acute biliary pancreatitis also increased with increment of WC $(\geq 94 \mathrm{~cm}$ in males and $\geq 80 \mathrm{~cm}$ in females:

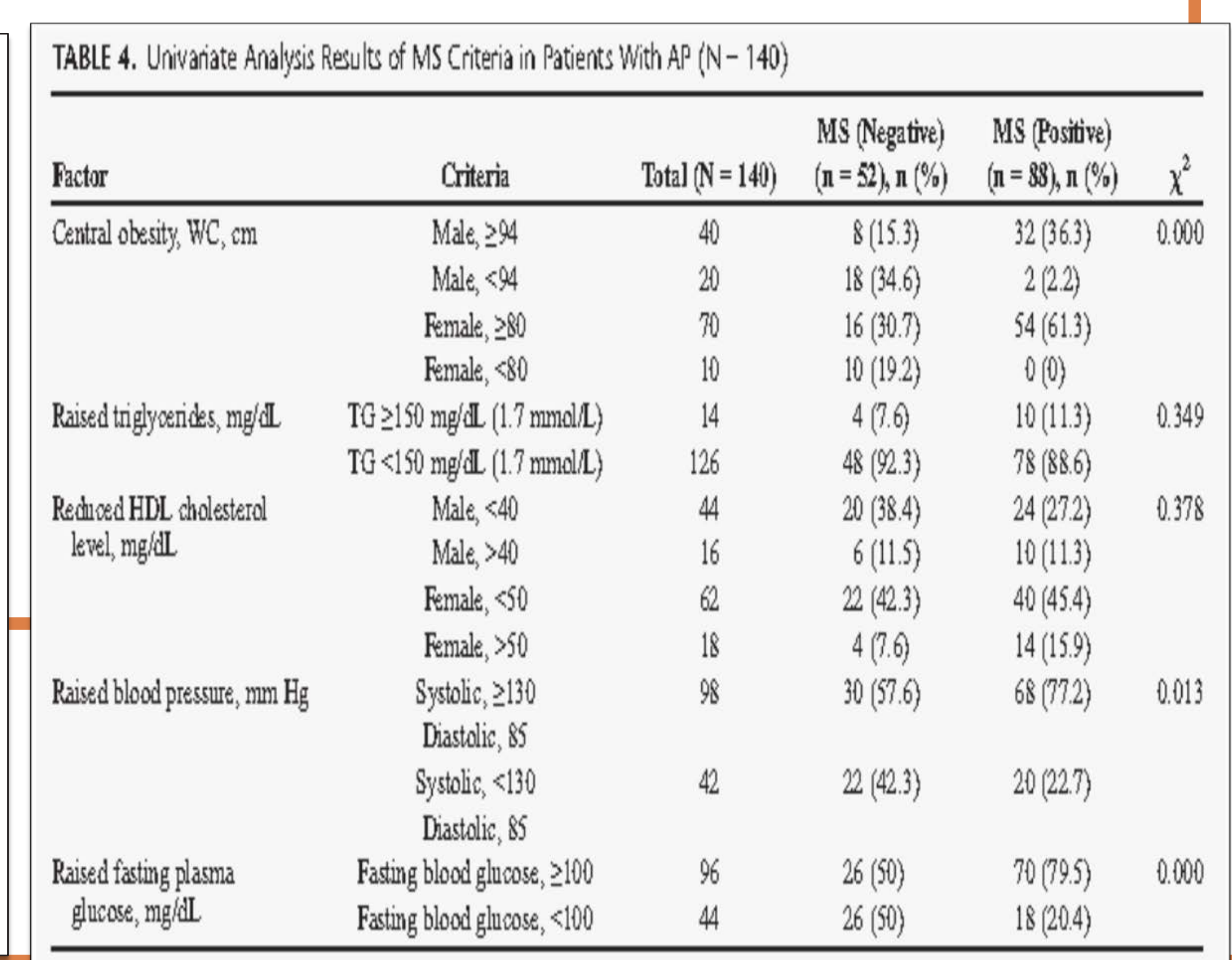

\section{References}

1-Papachristou GI, Papachristou DJ, Avula H, et al. Obesity increases
the severity of acute pancreatitis: performance of APACHE-O score

and correlation with the inflammatory response. Pancreatology.

2- Balthazar EJ, Ranson JH, Naidich DP, et al. Acute pancreatitis: prognostic value of CT. Radiology. 1985;156:767Y772.

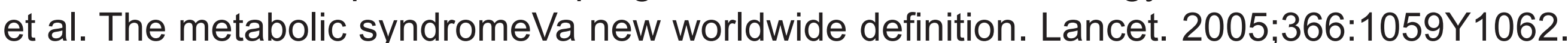

5- Lee YH, Pratley RE. The evolving role of inflammation in obesity and the metabolic syndrome. Curr Diab Rep. 2005;5:70Y75. 6 - Wang SQ, Li SJ, Feng QX, et al. Overweight is an additional prognostic factor in acute pancreatitis: a meta-analysis. Pancreatology.

7- Sempere L, Martinez J, de Madaria E, et al. Obesity and fat distribution imply a greater systemic inflammatory response and a worse prognosis in acute pan J, de Matis Pancreatology. 2008:8:257Y264.

8 - Mery CM, Rubio V, Duarte-Rojo A, et al. Android fat distribution as predictor of severity in acute pancreatitis. Pancreatology.

9- Bokova TA, Lebedeva AV.
Gastroenterol. 2012;1:19Y22. 